\title{
Oxidized Low-Density Lipoprotein (Ox-LDL) and Malondialdehyde (MDA) and Menopause: Loss of Protective Effect of Premenopuasl Status in Type 2 Diabetes Mellitus
}

Reyhane Hizomi Arani

Tehran University of Medical Sciences

Soghra Rabizadeh

Tehran University of Medical Sciences

Armin Rajab

Tehran University of Medical Sciences

Firuzeh Heidari

Tehran University of Medical Sciences

Alireza Esteghamati

Tehran University of Medical Sciences

Hossein Mirmiranpour

Tehran University of Medical Sciences

Minoosadat Hajmiri

Tehran University of Medical Sciences

manouchehr Nakhjavani ( $\square$ nakhjavanim@tums.ac.ir)

Tehran University of Medical Sciences

\section{Research}

Keywords: Oxidative stress, Menopause, Type 2 Diabetes mellitus, Oxidized low-density lipoprotein, Malondialdehyde, metabolic syndrome, 10-year risk score for atherosclerosis cardiovascular disease, Triglyceride

Posted Date: June 29th, 2020

DOI: https://doi.org/10.21203/rs.3.rs-37984/v1

License: (1) This work is licensed under a Creative Commons Attribution 4.0 International License. Read Full License 


\section{Abstract}

Background: A network of factors suggested to influence oxidative modification of serum low-density lipoprotein (ox-LDL) concentrations and it plays critical role in diabetic copmlications. This study aimed to assess the joint effect of Type 2 diabetes mellitus (T2DM), gender and menopausal status on ox-LDL and Malondialdehyde (MDA) levels.

Material and Method: A total of 594 female and male participants were divided into six groups: 189 postmenopausal women with T2DM, 79 premenopausal women with T2DM, 54 premenopausal women without T2DM, 53 postmenopausal women without T2DM, 186 men with T2DM and 33 men without T2DM. Laboratory and anthropometric measurements, metabolic syndrome (MetS) and the 10-year risk score for atherosclerotic cardiovascular disease (ASCVD) were assessed.

Results: Ox-LDL in women with T2DM was three times higher than women without T2DM. However, ox-LDL in men with T2DM was 1.3 times higher than men without T2DM. In non-T2DM participants, postmenopausal women had higher 10-year ASCVD risk score, concentrations of ox-LDL and MDA and higher prevalence of MetS compared to premenopausal women. However, this difference disappeared in participants with T2DM. In The interaction analysis did not show an additional effect of menopausal status and T2DM for ox-LDL and MDA serum levels in female participants (respectively $p=0.310, p=0.922$ ). In multivariate analysis, TG was independently associated with ox-LDL concentrations (OR: 1.27, $p \leq 0.001)$. In T-test analysis, participants with MetS, higher risk of ASCVD had higher levels of ox-LDL.

Conclusion: The magnitude of the increase in ox-LDL and MDA levels in women with T2DM was significantly higher than men with T2DM. The differences between pre- and postmenopausal women with and without T2DM in circulating ox-LDL and MDA mostly were dependent on T2DM, regardless of menopausal status. T2DM override the effect of menopausal status, gender and age on ox-LDL and MDA concentrations. Having MetS, increased TG levels and higher 10-year ASCVD risk score suggested to be associated with higher levels of ox-LDL.

\section{Background}

Oxidized low-density lipoprotein (ox-LDL) is produced from low-density lipoprotein cholesterol (LDL-C) under the oxidative condition and could lead to the sub-endothelial accumulation of foam cells. These foam cells take part in the evolvement of the fibro-fatty complex and atherosclerotic plaques [1]. Ox-LDL particles play an active role in developing endothelial dysfunction and atherosclerotic disease [2-6]. Holvet et al. indicated that the sensitivity of ox-LDL levels was higher than the Global Risk Assessment Score for Cardiovascular Risk prediction (GRAS) introduced for coronary artery disease (CAD) incidence [7]. Similar to ox-LDL, MDA is an end product of polyunsaturated fatty acid peroxidation and considered as an independent biochemical marker for atherosclerosis.[8].

The origin of ox-LDL is not entirely well-known. A network of risk factors suggested influencing ox-LDL concentrations, such as age, gender, T2DM, dyslipidemia, menopause, hypertension, and genetic predisposition. The role of T2DM on endothelial dysfunction has been well known [9-12]. Prolonged 
exposure to hyperglycemia in T2DM could increase the imbalance of oxidative and anti-oxidative markers. Ox-LDL may take part in the progression of the macrovascular and microvascular diseases such as diabetic nephropathy and neuropathy $[13,14]$.

Men have higher levels of peroxide productions and oxidative stress biomarkers in the vascular cells compared to women [15]. Moreover, clinical and experimental data reported more significant antioxidant potential in pre-menopausal women compared to men, which made women less susceptible to oxidative stress [16]. Some studies showed a lower risk and incidence of disease related to oxidative stress such as cardiovascular disease (CVD) in pre-menopausal women compared to age-matched men, with the gradual elimination of this gender-linked preference after menopause $[17,18]$.

The aim of this study was first; to assess the joint effect of T2DM, gender, menopausal status on serum oxLDL and MDA levels. Second, to examine serum levels of ox-LDL and MDA in pre- and post-menopausal women with and without T2DM compared to men with T2DM and non-diabetic male controls; third to evaluate independent risk factors, which predict serum level of ox-LDL.

\section{Methods}

Current study is a cross-sectional study conducted in the diabetes clinic of Vali-Asr Hospital affiliated with Tehran University of Medical Sciences (TUMS) in 2018. The study population consisted of 594 male and female participants selected from outpatients who attended our adult diabetes clinic and have similar environmental circumstances, lifestyle and diets. They divided into six groups of: 189 post-menopausal women with T2DM, 79 pre-menopausal women with T2DM, 54 pre-menopausal women without T2DM, 53 post-menopausal women without T2DM, 186 men with T2DM and 33 men without T2DM. The duration of T2DM ranged from 1 to 20 years. The participant's age was between 30-79 years. Diabetes was diagnosed according to the criteria of the American diabetes association (ADA) [19]. Menopause classification was based on women's history. The 10-year ASCVD risk score was defined as the risk of developing the first ASCVD event over a 10-year period which was calculated using the simplified scoring developed by American College of Cardiology/American Heart Association eigher for our diabetic and non-diabeteic participants [20]. Patients divided into fourgroups of low risk ( $<5 \%)$, borderline risk ( $5 \% \leq$ and $<7 \%$ ), intermediate-risk ( $7 \% \leq$ and $<19.5 \%)$, and high risk ( $\geq 19.5 \%)$. Exclusion criteria were smoking, pregnancy, proteinuria, renal involvement (creatinine $>1.5 \mathrm{mg} / \mathrm{dl}$ or glomerular filtration rate (GFR) $<70 \mathrm{cc} / \mathrm{min}$ ) and not having atherosclerotic cardiovascular disease (ASCVD) events at baseline. Also, women on hormone replacement therapy, ones at the age of menopause and women with history of surgical menopause were excluded. None of the patients with T2DM had any overt diabetic complications. Drug history, such as taking anti-hypertensive and lipid-lowering drugs, was not considered as a restriction for inclusion. The study complied with the principles of the Declaration of Helsinki [21]. The Local ethics review committee approved the study protocol. Written informed consent obtained from all patients.

\section{Anthropometric measurements}

Well-trained examiners conducted anthropometric measurements. We measured weight by a calibrated balance beam scale. Patients' heights were measured in centimetrs with shoes off and weights were 
measured in kilograms in indoor clothing. Body mass index (BMI) was calculated using the formula $\mathrm{BMI}=$ weight $(\mathrm{kg}) /$ height $^{2}\left(\mathrm{~m}^{2}\right)$. After 15 minutes of rest in the sitting position, blood pressure (BP) was applied to the right arm measured with a digital sphygmomanometer.

\section{Blood samples and laboratory evaluations}

Morning, blood samples collected after almost $12 \mathrm{~h}$ fasting, centrifuged and were kept at $-70^{\circ} \mathrm{C}$ until analysis. Fasting blood samples were obtained for measuring fasting blood sugar (FBS), total cholesterol, triglyceride (TG), high-density lipoprotein cholesterol (HDL-C), low-density lipoprotein cholesterol (LDL-C) and haemoglobin (HbA1c). Total cholesterol, HDL-C, and TG were measured by the Trinder method, immunoinhibitory method and enzymatic method respectively with the commercially available kit (Lipid, Pars Azmoon Co., Karaj, Iran). Also, LDL-C was calculated using the Friedewald formula. HbA1c was estimated by high-pressure liquid chromatography. Measurement of ox-LDL was performed using a commercially available sandwich ELISA method (Mercodia, Uppsala, Sweden) (Intra-assay CV $=4 \%$, interassay $\mathrm{CV}=7.3 \%$ ).

Metabolic syndrome (MetS) was defined based on the modified National Cholesterol Education Program Adult Treatment Panel III definition (NCEP ATP III)[22]. Participants with three or more than the five following criteria were considered as having the MetS: high BP $(\geq 130 / \geq 85 \mathrm{mmHg})$ or known hypertensive patients, elevated FBS ( $\geq 110 \mathrm{mg} / \mathrm{dl}$ ) or known diabetic patients, hypertriglyceridemia ( $\geq 150 \mathrm{mg} / \mathrm{dl})$, low HDL-C (women $<50 \mathrm{mg} / \mathrm{dl}$ and men $<40 \mathrm{mg} / \mathrm{dl}$ ), and high abdominal obesity (waist circumference $>88 \mathrm{~cm}$ for women and $>102$ for men). Measurements for Serum creatinine $(\mathrm{Cr})$ levels were done by kinetic colourimetric Jaffe with the sensitivity of $0.2 \mathrm{mg} / \mathrm{dL}$ (range $0.2-15 \mathrm{mg} / \mathrm{dL}$ ). The detection limit was 0.6 $\mathrm{mU} / \mathrm{l}$. Serum MDA was measured using a colourimetric method (Cayman, USA) with a dynamic assay range of 0-50 $\mu \mathrm{M}$ (Intra-assay CV= 5.5\%, inter-assay CV= 5.9\%).

\section{Statistical analysis}

The number of the patients(454) was estimated through the routine sample size calculation, (with alpha $=0.05$ and $d=0.05$, the prevalence of $62.22 \%$ for dyslipidemia in Iranian diabetic population-based on Janghorbani et al. study[23]. The statistical package SPSS 21 for windows (Chicago, Illinois, USA), was used for the analysis. Data were presented as mean \pm standard deviation for continuous and number (\%) for dichotomous variables. One-way analysis of variance (ANOVA), chi-square test, and T-test analysis were used for group comparisons, as appropriate. Pearson's correlation test was employed to study the correlation between ox-LDL, age, BMI, duration of T2DM, HbA1c, TG, LDL-C, HDL-C, MDA, MetS and 10-year risk score among our participants. The univariate and multivariate linear regression analysis was employed for data modelling. P-values $<0.05$ were considered statistically significant.

\section{Results}

\section{T2DM and Gender}


The study population consisted of 594 female and male participants. The baseline characteristics of the study population are presented in Table 1-4. Age, systolic blood pressure (SBP), TG, WC, HDL-C, FBS, HbA1C, the prevalence of MetS, and 10-year ASCVD risk score were significantly different between men and women with and without T2DM. Men and women with T2DM had 1.3 times and 3.0 times higher levels of ox-LDL compared to non-diabetic counterparts, respectively. Moreover, in patients with T2DM, women had about 1.2 times higher levels of ox-LDL in comparison with men (92.11 \pm 38.07 vs. 79.18 \pm 34.63$)$. However, in nondiabetic participants, men had about 1.8 times higher levels of ox-LDL in comparison with women (59.54 \pm 14.36 vs. $33.94 \pm 6.48$ ). Similar to ox-LDL, men and women with T2DM had increased levels of MDA in comparison to non-diabetic control groups ( $p=0.018$ and $p=0.001$ respectively)(figure 1$)$. In patients with T2DM, women had significantly higher levels of TG, HDL-C, the prevalence of MetS, and 10-year ASCVD risk score compared to men. However, in non-diabetic participants, men had significantly higher levels of TG, HDL-C, the prevalence of MetS and 10-year ASCVD risk score compared to women.

\section{T2DM and Menopause}

Comparing pre- and post-menopausal women with and without T2DM; age, SBP, WC, TG, HbA1C, ox-LDL, MDA levels, the prevalence of MetS, and 10-year ASCVD risk score were significantly different between the groups. Also, the duration of T2DM was significantly longer in post-menopausal women compared to premenopausal ones (median of 120.20 months (interquartile range [IQR], 72.00-156.00months) vs. median of 36.00 ([IQR], 2.40-96.00 months), p<0.001). Levels of ox-LDL, MDA, TG, 10-year ASCVD risk score, and the prevalence of MetS were more than two-fold higher in both pre-menopausal and post-menopausal patients with T2DM compared to non-diabetic women. Ox-LDL, MDA, 10-year ASCVD risk score, and the prevalence of MetS had no significant difference between pre- and post-menopausal women with T2DM. However, in non-diabetic participants, post-menopausal women had higher levels of MDA ( $1.95 \pm .0 .50 \mathrm{vs.} 1.90 \pm 0.93 \mathrm{vs}$.) and ox-LDL ( $37.48 \pm 6.48$ vs. $30.66 \pm 5.16$ ) compared to pre-menopausal ones(figure 1). Moreover, interaction analysis did not show additional effect between menopausal status and T2DM for serum levels of ox-LDL and MDA ( $p=0.310, p=0.922$ respectively) (figure2).

In both table1 and table3, BMI, diastolic blood pressure (DBP), LDL-C, total cholesterol, creatinine, family history of ASCVD, lipid lowering-drugs and glucose-lowering drugs were not significantly different between groups.

\section{Associations}

The ox-LDL levels were significantly correlated with TG $(r=0.68, p \leq 0.001), \operatorname{HbA1c}(r=0.23, p \leq 0.001)$, FBS $(r=0.29, p \leq 0.001)$, MetS $(r=0.61, p \leq 0.001)$ and 10-year ASCVD risk score $(r=0.82, p<0.001)$. In T-test analysis, participants with MetS had higher levels of ox-LDL ( $p=0.003$; not shown in tables).Aslo, ox-LDL was significantly different among the ASCVD risk groups (figure 3).In univariate linear regression age, HDLC, SBP, TG, FBS, HbA1c, and 10-year ASCVD risk score were significantly associated with ox-LDL levels ( $p$ $\leq 0.001$ ) (table 5). In multivariate analysis, TG remained the strongest factor which significantly associated with circulating ox-LDL concentrations between our groups (OR: 1.27, $p \leq 0.001$ ) (table 5). In linear regression, ox-LDL and MDA were significantly different between participants with and without T2DM after adjustment for age $(R=0.514, p \leq 0.001)$. 


\section{Discussion}

In the present study, T2DM overrided the effect of menopausal status, gender, and ageing on ox-LDL and MDA concentrations. In participants without T2DM, ox-LDL was 1.8 times higher in men compared to women; however, in participants without T2DM, ox-LDL was about 1.2 higher in women in comparison with men. The magnitude of the increase in ox-LDL and MDA levels in women with T2DM was significantly higher than men with T2DM. Diabetes could increase the concentration of lipid peroxidation products following the impairment of oxidation/ anti-oxidation balance induced by prolonged exposure to hyperglycemia [24]. Here we observed that diabetes could eliminate the protective effect of female sex on ox-LDL and MDA and reverse the difference between men and women.

Our results indicated that although ox-LDL and MDA were higher in post-menopausal women without T2DM, this difference was disappeared in patients with T2DM, either pre- or post-menopausal (figure1). Yichuan Wen et al. reported that ox-LDL mainly increased following menopause in non-diabetic women due to loss of anti-oxidative properties of estrogen after menopause [25] similar to MDA [26]. The interaction analysis showed that T2DM and menopausal status had no significant joint effects on ox-LDL and MDA levels.

The current study showed that ox-LDL levels had a powerful association with the 10-year ASCVD risk score. This result could support previous researches showing the association of cardiovascular events and ox-LDL concentration $[27,28]$. In our study, men with T2DM had a lower 10-year ASCVD risk score compared to women; while among participants without T2DM, men had a higher 10-year ASCVD risk score compared to women. Some population-based studies have shown that diabetes imposes a greater risk of CVD in women than in men $[29,30]$. It may suggest that diabetes could change the gender difference in ASCVD predisposition under the influence of ox-LDL levels. Moreover, our result indicated that the 10-year ASCVD risk score was higher in postmenopausal women without T2DM, while this difference was not present in patients with T2DM either pre- or post-menopausal. The same incidence of myocardial infarction in pre- and postmenopausal women with T2DM could support this issue [31]. It could be stated that diabetes could eliminate the difference between pre- and postmenopausal women in ASCVD events subsequently by changing in ox-LDL levels.

Our result indicated that ox-LDL levels were higher among participants with MetS compared to participants without MetS. In this line, Holvoet et al. mentioned that individuals with the MetS had two-fold more elevated levels of ox-LDL compared to those without MetS, independent of age, sex, ethnicity, LDL-C, and smoking status[32]. A population-based cohort study showed that higher concentrations of circulating ox-LDL are associated with the incidence of MetS as well as the accumulation of three of its component:

hyperglycemia, abdominal obesity, and hyperglycemia [33]. In consistence with a meta-analysis report, in participants without T2DM, MetS was more prevalent among post-menopausal women compared to premenopausal[34] while participants with T2DM had the similar incidence of MetS. Based on our analysis, this difference was more attributed to BP among the components of MetS. It seems that T2DM made premenopausal women more susceptible to hypertension and the incidence of MetS as a result.

Our multivariate linear regression analysis showed that TG was an independent predictor for ox-LDL levels after adjusting for age, BMI, WC, duration of diabetes, SBP, HDL-C, LDL-C, FBS and HbA1c. We previously 
mentioned the higher prevalence of hypertriglyceridemia in women with T2DM compared to men with T2DM [35]. Several studies have demonstrated the association between TG and oxidative markers [33, 36]. As plasma oxidized lipids have a relation with future subclinical and clinical atherosclerosis [14, 37]; this result could justify the long-standing association between hypertriglyceridemia and CVD [38, 39]. In this regard, the results of a decade follow-up of the Iranian population revealed that the increased risk for coronary heart disease (CHD) was attributed to TG [40]. A possible explanation is that higher TG levels in plasma could enhance the production of small, dense LDL particles, which are known to be more susceptible to oxidation [33].

Another important finding is that although the ox-LDL/LDL, as a lipid biomarker for estimation of oxidation[41], was significantly different among the participants, mean levels of total cholesterol and LDL-C did not differ by gender and T2DM status in this study. Infact, we found no significant correlation between ox-LDL and LDL-C. Moreover, ox-LDL and MDA were not significantly different between patients who were and were not treated by lipid-lowering drugs. This finding is aligned with our previous study suggesting that maintaining an optimized level of $L D L-C$, according to guidelines for the management of lipids in patients with T2DM does not sufficiently influence the ox-LDL levels [42].

The strength of this research was an adequate sample size to show the age-adjusted joint effect of diabetes, menopausal status, and gender and the independent association of TG on serum ox-LDL levels. The current research was a cross-section from a cohort study, so the main limitation was the lack of follow-up of the patients. Also, accurate analysis of lipid peroxidation like MDA and ox-LDL in serum is confounded by enzymatic and non-enzymatic lipid peroxidation that occurs during serum formation. So further studies should be conducted using plasma to handle procedures for prevention of lipid peroxidation.

In conclusion, T2DM overrides the effect of menopausal status, gender, and age on ox-LDL and MDA concentrations. Differences between women in circulating ox-LDL and MDA mostly dependent on T2DM, regardless of menopausal status and ageing. Besides, TG was independently associated with ox-LDL concentration. Also, we could show a positive correlation between 10-year ASCVD risk score and MetS with serum levels of ox-LDL.

\section{Abbreviations}

Oxidized low-density lipoprotein: ox-LDL; Type 2 diabetes mellitus: T2DM; Malondialdehyde: MDA; Metabolic syndrome: MetS; Atherosclerotic cardiovascular disease: ASCVD

\section{Declarations}

\section{Ethics approval and consent to participate}

All work was conducted in accordance with the Code of Ethics of the World Medical Association Helsinki Declaration. The privacy and rightsof all subjects were preserved 


\section{Consent for publication}

Not Applicable.

\section{Availability of data materials}

The dataset supporting the conclusions of this article is included within the article.

\section{Competing interests}

The authors declare that they have no competing interests.

\section{Funding}

Not Applicable.

\section{Authors' contributions}

RHA contributed to conception and design, development of methodology, analysis and interpretation of data, and drafting and re-vision of the manuscript, SR contributed to conception and design, develop-ment of methodology.AR contributed to development of methodology and analysis and interpretation of data. $\mathrm{FH}$ and $\mathrm{HM}$ contributed to drafting and revision of the manuscript. $\mathrm{AE}$ and $\mathrm{MH}$ contributed to acquisition of data, analysis and interpretation of data, drafting and revision of the manuscript, and study supervision. MN contributed to conception and design, developmentof methodology, analysis and interpretation of data, drafting and re-vision of the manuscript, and study supervision. Manouchehr Nakhjavani had full access to all of the data in the study and takes responsibility for the integrity of the data and the accuracy of the analysis.

\section{Acknowledgement:}

Research is reported in this publication was supported by Elite Researcher Grant Committee under award number 982826 from the National Institutes for Medical Research Development (NIMAD), Tehran, Iran.

\section{References}

1. Ross R: The pathogenesis of atherosclerosis: a perspective for the 1990s. Nature 1993, 362:801.

2. Holvoet P, Vanhaecke J, Janssens S, Van de Werf F, Collen D: Oxidized LDL and malondialdehydemodified LDL in patients with acute coronary syndromes and stable coronary artery disease.Circulation 1998, 98:1487-1494.

3. Lamarche B, Tchernof A, Mauriege P, Cantin B, Dagenais GR, Lupien PJ, Després J-P: Fasting insulin and apolipoprotein $B$ levels and low-density lipoprotein particle size as risk factors for ischemic heart disease.Jama 1998, 279:1955-1961. 
4. Lamarche B, Tchernof A, Moorjani S, Cantin B, Dagenais GR, Lupien PJ, Despre' s J-P: Small, dense lowdensity lipoprotein particles as a predictor of the risk of ischemic heart disease in men: prospective results from the Qué bec Cardiovascular Study.Circulation 1997, 95:69-75.

5. Stampfer MJ, Krauss RM, Ma J, Blanche PJ, Holl LG, Sacks FM, Hennekens CH: A prospective study of triglyceride level, low-density lipoprotein particle diameter, and risk of myocardial infarction.Jama 1996, 276:882-888.

6. Gardner CD, Fortmann SP, Krauss RM: Association of small low-density lipoprotein particles with the incidence of coronary artery disease in men and women.Jama 1996, 276:875-881.

7. Holvoet P, Mertens A, Verhamme P, Bogaerts K, Beyens G, Verhaeghe R, Collen D, Muls E, Van de Werf F: Circulating oxidized LDL is a useful marker for identifying patients with coronary artery disease.Arteriosclerosis, thrombosis, and vascular biology 2001, 21:844-848.

8. Holvoet P, Perez G, Zhao Z, Brouwers E, Bernar H, Collen D: Malondialdehyde-modified low density lipoproteins in patients with atherosclerotic disease. The Journal of clinical investigation 1995, 95:26112619.

9. Stranges S, Rafalson LB, Dmochowski J, Rejman K, Tracy RP, Trevisan M, Donahue RP: Additional contribution of emerging risk factors to the prediction of the risk of type 2 diabetes: evidence from the Western New York Study.Obesity 2008, 16:1370-1376.

10. Song Y, Manson JE, Tinker L, Rifai N, Cook NR, Hu FB, Hotamisligil GS, Ridker PM, Rodriguez BL, Margolis KL: Circulating levels of endothelial adhesion molecules and risk of diabetes in an ethnically diverse cohort of women.Diabetes 2007, 56:1898-1904.

11. Thorand B, Baumert J, Chambless L, Meisinger C, Kolb H, Doring A, Löwel H, Koenig W: Elevated markers of endothelial dysfunction predict type 2 diabetes mellitus in middle-aged men and women from the general population.Arteriosclerosis, thrombosis, and vascular biology 2006, 26:398-405.

12. Meigs JB, Hu FB, Rifai N, Manson JE: Biomarkers of endothelial dysfunction and risk of type 2 diabetes mellitus.Jama 2004, 291:1978-1986.

13. Ujihara N, Sakka Y, Takeda M, Hirayama M, Ishii A, Tomonaga O, Babazono T, Takahashi C, Yamashita $\mathrm{K}$, Iwamoto Y: Association between plasma oxidized low-density lipoprotein and diabetic nephropathy.Diabetes research and clinical practice 2002, 58:109-114.

14. Tsuzura S, Ikeda Y, Suehiro T, Ota K, Osaki F, Arii K, Kumon Y, Hashimoto K: Correlation of plasma oxidized low-density lipoprotein levels to vascular complications and human serum paraoxonase in patients with type 2 diabetes.Metabolism 2004, 53:297-302.

15. Brunelli E, Domanico F, La Russa D, Pellegrino D: Sex differences in oxidative stress biomarkers. Current drug targets 2014, 15:811-815.

16. Intapad S, Ojeda NB, Dasinger JH, Alexander BT: Sex differences in the developmental origins of cardiovascular disease.Physiology 2014, 29:122-132.

17. Cervellati C, Bergamini CM: Oxidative damage and the pathogenesis of menopause related disturbances and diseases.Clinical Chemistry and Laboratory Medicine (CCLM) 2016, 54:739-753.

18. Doshi SB, Agarwal A: The role of oxidative stress in menopause.Journal of mid-life health 2013, 4:140. 
19. Buse JB, Wexler DJ, Tsapas A, Rossing P, Mingrone G, Mathieu C, D’Alessio DA, Davies MJ: 2019 update to: Management of hyperglycaemia in type 2 diabetes, 2018. A consensus report by the American Diabetes Association (ADA) and the European Association for the Study of Diabetes (EASD).Diabetologia 2020, 63:221-228.

20. Goff DC, Lloyd-Jones DM, Bennett G, Coady S, D'agostino RB, Gibbons R, Greenland P, Lackland DT, Levy D, O'donnell CJ: 2013 ACC/AHA guideline on the assessment of cardiovascular risk: a report of the American College of Cardiology/American Heart Association Task Force on Practice Guidelines.Journal of the American College of Cardiology 2014, 63:2935-2959.

21. Association WM: Declaration of Helsinki. Ethical principles for medical research involving human subjects.http://www wma net/e/policy/b3 htm 2008.

22. Expert Panel on Detection E: Executive summary of the third report of the National Cholesterol Education Program (NCEP) expert panel on detection, evaluation, and treatment of high blood cholesterol in adults (Adult Treatment Panel III).Jama 2001, 285:2486.

23. Janghorbani $M$, Amini M: Metabolic syndrome in type 2 diabetes mellitus in isfahan, iran: prevalence and risk factors.Metab Syndr Relat Disord 2007, 5:243-254.

24. Asmat U, Abad K, Ismail K: Diabetes mellitus and oxidative stress-A concise review.Saudi Pharmaceutical Journal 2016, 24:547-553.

25. Wen Y, Doyle MC, Cooke T, Feely J: Effect of menopause on low-density lipoprotein oxidation: is oestrogen an important determinant? Maturitas 2000, 34:233-238.

26. Cakir T, Goktas B, Mutlu MF, Mutlu I, Bilgihan A, Erdem M, Erdem A: Advanced oxidation protein products and malondialdehyde-the new biological markers of oxidative stress-are elevated in postmenopausal women.Ginekologia polska 2016, 87:321-325.

27. Trpkovic A, Resanovic I, Stanimirovic J, Radak D, Mousa SA, Cenic-Milosevic D, Jevremovic D, Isenovic ER: Oxidized low-density lipoprotein as a biomarker of cardiovascular diseases. Critical reviews in clinical laboratory sciences 2015, 52:70-85.

28. Holvoet P, Jenny NS, Schreiner PJ, Tracy RP, Jacobs DR, Atherosclerosis M-ESo: The relationship between oxidized LDL and other cardiovascular risk factors and subclinical CVD in different ethnic groups: the Multi-Ethnic Study of Atherosclerosis (MESA).Atherosclerosis 2007, 194:245-252.

29. Peters SA, Huxley RR, Woodward M: Diabetes as risk factor for incident coronary heart disease in women compared with men: a systematic review and meta-analysis of 64 cohorts including 858,507 individuals and 28,203 coronary events. Springer; 2014.

30. Peters SA, Huxley RR, Woodward M: Diabetes as a risk factor for stroke in women compared with men: a systematic review and meta-analysis of 64 cohorts, including 775385 individuals and 12539 strokes. The Lancet 2014, 383:1973-1980.

31. Nakhjavani M, Imani M, Larry M, Aghajani-Nargesi A, Morteza A, Esteghamati A: Metabolic syndrome in premenopausal and postmenopausal women with type 2 diabetes: loss of protective effects of premenopausal status.Journal of Diabetes \& Metabolic Disorders 2014, 13:102.

32. Holvoet P, Kritchevsky SB, Tracy RP, Mertens A, Rubin SM, Butler J, Goodpaster B, Harris TB: The metabolic syndrome, circulating oxidized LDL, and risk of myocardial infarction in well-functioning 
elderly people in the health, aging, and body composition cohort.Diabetes 2004, 53:1068-1073.

33. Holvoet P, Lee D-H, Steffes M, Gross M, Jacobs DR: Association between circulating oxidized lowdensity lipoprotein and incidence of the metabolic syndrome.Jama 2008, 299:2287-2293.

34. Hallajzadeh J, Khoramdad M, Izadi N, Karamzad N, Almasi-Hashiani A, Ayubi E, Qorbani M, Pakzad R, Hasanzadeh A, Sullman MJ: Metabolic syndrome and its components in premenopausal and postmenopausal women: a comprehensive systematic review and meta-analysis on observational studies.Menopause 2018, 25:1155-1164.

35. Nakhjavani M, Esteghamati A, Heshmat FEA: Dyslipidemia in type 2 diabetes mellitus: more atherogenic lipid profile in women.Acta Medica Iranica 2006:111-118.

36. Lapointe A, Couillard C, Piché M-È, Weisnagel SJ, Bergeron J, Nadeau A, Lemieux S: Circulating oxidized LDL is associated with parameters of the metabolic syndrome in postmenopausal women.Atherosclerosis 2007, 191:362-368.

37. Lim SC, Caballero AE, Arora S, Smakowski P, Bashoff EM, Brown FM, Logerfo FW, Horton ES, Veves A: The effect of hormonal replacement therapy on the vascular reactivity and endothelial function of healthy individuals and individuals with type 2 diabetes. The Journal of Clinical Endocrinology \& Metabolism 1999, 84:4159-4164.

38. Murad MH, Hazem A, Coto-Yglesias F, Dzyubak S, Gupta S, Bancos I, Lane MA, Erwin PJ, Berglund L, Elraiyah T: The association of hypertriglyceridemia with cardiovascular events and pancreatitis: a systematic review and meta-analysis.BMC endocrine disorders 2012, 12:2.

39. Hokanson JE, Austin MA: Plasma triglyceride level is a risk factor for cardiovascular disease independent of high-density lipoprotein cholesterol level: a metaanalysis of population-based prospective studies. Journal of cardiovascular risk 1996, 3:213-219.

40. Ghasemzadeh Z, Abdi H, Asgari S, Tohidi M, Khalili D, Valizadeh M, Moeini S, Eidkhani V, Azizi F, Hadaegh F: Divergent pathway of lipid profile components for cardiovascular disease and mortality events: Results of over a decade follow-up among Iranian population.Nutrition \& metabolism 2016, $13: 43$

41. Motamed M, Nargesi AA, Heidari B, Mirmiranpour H, Esteghamati A, Nakhjavani M: Oxidized LowDensity Lipoprotein (ox-LDL) to LDL Ratio (ox-LDL/LDL) and ox-LDL to High-Density Lipoprotein Ratio (ox-LDL/HDL).Clinical laboratory 2016, 62:1609.

42. Nakhjavani M, Khalilzadeh O, Khajeali L, Esteghamati A, Morteza A, Jamali A, Dadkhahipour S: Serum oxidized-LDL is associated with diabetes duration independent of maintaining optimized levels of LDLcholesterol.Lipids 2010, 45:321-327.

\section{Tables}

Table 1.Baseline characteristics of men and women with and without type 2 diabetes 


\begin{tabular}{|c|c|c|c|c|c|}
\hline & \multicolumn{2}{|c|}{ T2DM } & \multicolumn{2}{|c|}{ Non-T2DM } & \multirow{3}{*}{$\begin{array}{l}\mathrm{p}- \\
\text { value }\end{array}$} \\
\hline & women & Men & women & Men & \\
\hline & $N=268$ & $N=186$ & $N=107$ & $N=33$ & \\
\hline Age (years) & $54.51 \pm 9.06$ & $56.47 \pm 10.67 \&$ & $50.82 \pm 8.81$ & $52.39 \pm 6.26$ & 0.011 \\
\hline $\mathrm{BMI}\left(\mathrm{kg} / \mathrm{m}^{2}\right)$ & $25.83 \pm 4.22$ & $26.05 \pm 4.86$ & $26.15 \pm 4.07$ & $26.67 \pm 2.60$ & 0.351 \\
\hline $\mathrm{SBP}(\mathrm{mmHg})$ & $129.74 \pm 17.56$ & $134.84 \pm 17.44^{\wedge}$ & $126.65 \pm 15.88$ & $120.94 \pm 10.47$ & 0.008 \\
\hline $\mathrm{DBP}(\mathrm{mmHg})$ & $83.89 \pm 13.37$ & $86.65 \pm 21.10$ & $80.05 \pm 8.82$ & $85.45 \pm 7.47$ & 0.326 \\
\hline $\mathrm{WC}(\mathrm{cm})$ & $88.41 \pm 21.71$ & $92.42 \pm 25.31 \&$ & $82.97 \pm 22.43$ & $87.01 \pm 19.13$ & 0.046 \\
\hline $\begin{array}{l}\text { Duration of } \\
\text { diabetes } \\
\text { (months) }\end{array}$ & $\begin{array}{l}96.21 \\
(24.23,144.07)\end{array}$ & $\begin{array}{l}108.02 \\
(48.06,150.11)\end{array}$ & - & - & 0.275 \\
\hline $\begin{array}{l}\text { Family history } \\
\text { of ASCVD, } \\
\mathrm{n}(\%)\end{array}$ & $35(13.0)$ & $23(12.3)$ & $11(10.2)$ & $4(12.1)$ & 0.481 \\
\hline TG (mg/dl) & $196.96 \pm 95.61 \&^{\wedge \star}$ & $164.63 \pm 77.86 \&^{\wedge}$ & $80.63 \pm 23.08^{\wedge}$ & $126.24 \pm 51.07$ & $<0.001$ \\
\hline LDL-C (mg/dl) & $97.82 \pm 29.32$ & $99.08 \pm 32.72$ & $103.12 \pm 20.41$ & $103.28 \pm 23.23$ & 0.235 \\
\hline HDL-C (mg/dl) & $42.62 \pm 13.51 \&^{\wedge \star}$ & $38.36 \pm 11.51 \&^{\wedge}$ & $49.08 \pm 11.51^{\wedge}$ & $48.41 \pm 15.36$ & $<0.001$ \\
\hline $\begin{array}{l}\text { Total } \\
\text { cholesterol } \\
(\mathrm{mg} / \mathrm{dl})\end{array}$ & $203.04 \pm 52.80$ & $193.42 \pm 48.36$ & $209.45 \pm 32.06$ & $195.75 \pm 37.84$ & 0.659 \\
\hline $\mathrm{FBS}(\mathrm{mg} / \mathrm{dl})$ & $183.21 \pm 63.40 \&^{\wedge}$ & $179.09 \pm 61.86 \&^{\wedge}$ & $90.50 \pm 24.27$ & $88.01 \pm 8.85$ & $<0.001$ \\
\hline Creatinine & $0.94 \pm 0.31$ & $0.97 \pm 0.22$ & $0.90 \pm 0.13$ & $0.99 \pm 0.19$ & 0.268 \\
\hline HbA1c (\%) & $8.25 \pm 1.75 \&^{\wedge}$ & $8.23 \pm 1.94 \&^{\wedge}$ & $4.90 \pm 0.33$ & $5.15 \pm 0.30$ & $<0.001$ \\
\hline MDA(IU/I) & $3.90 \pm 0.97 \&^{\wedge \star}$ & $3.13 \pm 1.32 \&^{\wedge}$ & $1.96 \pm 0.58^{\wedge}$ & $2.63 \pm 1.45$ & $<0.001$ \\
\hline Ox-LDL(mU/I) & $92.11 \pm 38.07 \&^{\wedge \star}$ & $79.18 \pm 34.63 \&^{\wedge}$ & $33.94 \pm 6.48^{\wedge}$ & $59.54 \pm 14.36$ & $<0.001$ \\
\hline Ox-LDL/ LDL-C & $1.04 \pm 0.96 \&^{\wedge}$ & $0.90 \pm 0.53 \&^{\wedge}$ & $0.33 \pm 0.09^{\wedge}$ & $0.60 \pm 0.19$ & $<0.001$ \\
\hline $\begin{array}{l}\text { Glucose- } \\
\text { lowering } \\
\text { medication }\end{array}$ & & & & & 0.198 \\
\hline - OAD, n(\%) & $123(45.8)$ & $98(52.6)$ & & & \\
\hline - Insulin, n(\%) & 102(38.0) & $59(31.7)$ & & & \\
\hline $\begin{array}{l}\text {-Insulin+OAD, } \\
n(\%)\end{array}$ & $39(14.5)$ & 22(11.8) & & & \\
\hline $\begin{array}{l}\text { Lipid-lowering } \\
\text { medication, } \\
\mathrm{n}(\%)\end{array}$ & $111(41.4)$ & $101(54.3)$ & $44(41.1)$ & $15(45.4)$ & 0.273 \\
\hline
\end{tabular}


Data are presented as mean \pm SD and percent $(\%)$, duration of diabetes presented as median (interquartile range[IQR])

$\& p<0.05$ vs. female patients without T2DM

${ }^{\wedge} \mathrm{p}<0.05$ vs. male patients without T2DM

* $p<0.05$ vs. male patients with T2DM

$\mathrm{BMI}=$ Body mass index; $\mathrm{SBP}=$ systolic blood pressure; $\mathrm{DBP}=$ Diastolic blood pressure; $\mathrm{WC}=$ waist circumference; $T G=$ triglyceride; $L D L-C=L$ ow dense lipoprotein; HDL-C=high dense lipoprotein; MDA= Malondialdehyde; FBS=Fasting blood sugar; $\mathrm{HbA} 1 \mathrm{c}=$ hemoglobin A1c; ox-LDL= oxidized Low dense lipoprotein; OAD=Oral Antidiabetic Drugs, n= number

Table 2. Ten-year ASCVD risk score and metabolic syndrome of men and women with and without T2DM

\begin{tabular}{|c|c|c|c|c|c|}
\hline & T2DM & & Non-T2DM & & \\
\hline & women & Men & women & Men & $\mathrm{p}-$ \\
\hline & $N=268$ & $\mathrm{~N}=186$ & $\mathrm{~N}=107$ & $N=33$ & \\
\hline 10-year ASCVD risk & $10.36 \pm 6.88 \&^{\wedge}$ & $8.39 \pm 5.91 \&^{\wedge}$ & $2.85 \pm 0.48^{\wedge}$ & $4.24 \pm 1.24$ & $<0.001$ \\
\hline score(\%) & & & & & \\
\hline Risk groups, $\mathrm{n}(\%)$ & & & & & 0.034 \\
\hline - Low risk $(<5 \%)$ & $61(23.7) \&^{\wedge}$ & $34(18.2) \&^{\wedge}$ & $73(68.2)^{\wedge}$ & $19(57.5)$ & \\
\hline - Borderline risk $(5 \% \leq$ and $<7 \%)$ & $25(9.3)$ & $12(6.4)$ & $10(9.3)$ & $3(9.0)$ & \\
\hline $\begin{array}{l}\text { - Intermediate risk }(7 \% \leq \text { and } \\
<19.5 \%)\end{array}$ & $84(31.3) \&^{\wedge \star}$ & $46(24.7) \&^{\wedge}$ & 14(13.0) & $5(15.1)$ & \\
\hline - High risk ( $\geq 19.5 \%)$ & $103(38.4) \&^{\wedge \star}$ & $54(29.0) \&^{\wedge}$ & $15(14.0)^{\wedge}$ & $7(21.2)$ & \\
\hline Metabolic syndrome, n(\%) & $235(87.6) \&^{\wedge \star}$ & $145(77.9) \&^{\wedge}$ & $42(39.2)^{\wedge}$ & $8(24.2)$ & 0.002 \\
\hline
\end{tabular}

Table3. Baseline characteristics of Premenopausal and Postmenopausal women with T2DM (268) and without T2DM (107) 


\begin{tabular}{|c|c|c|c|c|c|}
\hline & T2DM & & Non-T2DM & & \\
\hline & $\begin{array}{l}\text { Premenopausal } \\
\text { women }\end{array}$ & $\begin{array}{l}\text { Postmenopausal } \\
\text { women }\end{array}$ & $\begin{array}{l}\text { Premenopausal } \\
\text { women }\end{array}$ & $\begin{array}{l}\text { Postmenopausal } \\
\text { women }\end{array}$ & $\begin{array}{l}\mathrm{p}- \\
\text { value }\end{array}$ \\
\hline & $N=79$ & $N=189$ & $\mathrm{~N}=54$ & $N=79$ & \\
\hline Age (years) & $42.59 \pm 5.28 \#$ & $58.85 \pm 7.22 * \&$ & $43.33 \pm 4.40 \#$ & $56.43 \pm 5.81$ & $<0.001$ \\
\hline $\begin{array}{l}\mathrm{BMI} \\
\left(\mathrm{kg} / \mathrm{m}^{2}\right)\end{array}$ & $25.70 \pm 5.48$ & $27.22 \pm 4.42$ & $25.10 \pm 4.40$ & $26.27 \pm 4.07$ & 0.164 \\
\hline $\begin{array}{l}\text { SBP } \\
(\mathrm{mmHg})\end{array}$ & $121.22 \pm 16.31$ & $132.73 \pm 19.52^{\star}$ & $130.32 \pm 17.82$ & $127.14 \pm 11.88$ & 0.028 \\
\hline $\begin{array}{l}\text { DBP } \\
(\mathrm{mmHg})\end{array}$ & $86.01 \pm 20.60$ & $83.07 \pm 10.37$ & $80.07 \pm 8.78$ & $82.02 \pm 8.81$ & 0.141 \\
\hline $\mathrm{WC}(\mathrm{cm})$ & $87.3 \pm 23.19$ & $89.11 \pm 18.71 \&$ & $81.87 \pm 20.31$ & $85.17 \pm 19.72$ & 0.032 \\
\hline $\begin{array}{l}\text { Duration of } \\
\text { T2DM } \\
\text { (months) }\end{array}$ & $\begin{array}{l}36.00(2.40 \\
96.00)\end{array}$ & $\begin{array}{l}120.00 \\
(72.00,156.00)^{*}\end{array}$ & - & - & $<0.001$ \\
\hline $\begin{array}{l}\text { Duration of } \\
\text { menopause } \\
\text { (years) }\end{array}$ & - & $8.70(3.70,12.70)$ & - & $5.70(2.70,11.70)$ & 0.321 \\
\hline $\begin{array}{l}\text { Family } \\
\text { history of } \\
\text { ASCVD, } \\
n(\%)\end{array}$ & $7(8.8)$ & 19(10.0) & $5(9.2)$ & $5(9.4)$ & 0.542 \\
\hline $\mathrm{TG}(\mathrm{mg} / \mathrm{dl})$ & $207.95 \pm 122.16 \& \#$ & $192.54 \pm 82.88 \& \#$ & $80.18 \pm 23.95$ & $81.07 \pm 24.00$ & $<0.001$ \\
\hline $\begin{array}{l}\text { LDL-C } \\
(\mathrm{mg} / \mathrm{dl})\end{array}$ & $100.27 \pm 22.15$ & $96.72 \pm 31.32$ & $104.58 \pm 22.91$ & $101.31 \pm 16.42$ & 0.134 \\
\hline $\begin{array}{l}\mathrm{HDL-C} \\
(\mathrm{mg} / \mathrm{dl})\end{array}$ & $42.59 \pm 16.60 \&$ & $42.77 \pm 12.62 \&$ & $48.72 \pm 11.54$ & $47.10 \pm 9.52$ & 0.049 \\
\hline $\begin{array}{l}\text { Total } \\
\text { cholesterol } \\
(\mathrm{mg} / \mathrm{dl})\end{array}$ & $206.44 \pm 36.41$ & $201.51 \pm 48.80$ & $203.81 \pm 46.31$ & $215.56 \pm 44.65$ & 0.955 \\
\hline $\begin{array}{l}\text { FBS } \\
(\mathrm{mg} / \mathrm{dl})\end{array}$ & $191.53 \pm 71.81 \# \&$ & $179.65 \pm 60.40 \# \&$ & $87.58 \pm 8.7$ & $94.10 \pm 35.38$ & $<0.001$ \\
\hline Creatinine & $0.90 \pm 0.18$ & $0.96 \pm 0.33$ & $0.88 \pm 0.11$ & $0.92 \pm 0.15$ & 0.231 \\
\hline $\mathrm{HbA1c}(\%)$ & 8. $21 \pm 2.33 \# \&$ & $8.26 \pm 1.75 \# \&$ & $4.83 \pm 0.39$ & $4.99 \pm 0.26$ & $<0.001$ \\
\hline MDA(IU/I) & $3.86 \pm 0.96 \& \#$ & $3.89 \pm 1.00 \& \#$ & $1.90 \pm 0.93 \#$ & $1.95 \pm .0 .50$ & $<0.001$ \\
\hline $\begin{array}{l}\text { Ox- } \\
\mathrm{LDL}(\mathrm{mU} / \mathrm{l})\end{array}$ & $91.38 \pm 34.73 \& \#$ & $92.08 \pm 39.40 \& \#$ & $30.66 \pm 5.16 \#$ & $37.48 \pm 6.48$ & $<0.001$ \\
\hline $\begin{array}{l}\text { Ox- } \\
\text { LDL/LDL }\end{array}$ & $0.89 \pm 0.42 \& \#$ & $1.01 \pm 0.57 \& \#$ & $0.30 \pm 0.07$ & $0.37 \pm 0.09$ & $<0.001$ \\
\hline
\end{tabular}




\begin{tabular}{|c|c|c|c|c|c|}
\hline - OAD, n(\%) & $38(48.1)$ & $77(40.7)$ & & & \\
\hline $\begin{array}{l}\text { - Insulin, } \\
\text { n(\%) }\end{array}$ & $17(21.5)$ & $56(29.6)$ & & & \\
\hline $\begin{array}{l}\text { - Insulin } \\
+0 A D, n(\%)\end{array}$ & $10(12.6)$ & $27(14.2)$ & & & \\
\hline $\begin{array}{l}\text { Lipid- } \\
\text { lowering } \\
\text { medication } \\
\text { use, n(\%) }\end{array}$ & $24(30.3)$ & $80(42.3)$ & 18(33.3) & $20(37.7)$ & 0.256 \\
\hline
\end{tabular}

Data are presented as mean \pm SD and percent (\%) duration of diabetes and menopause presented as median (interquartile range[IQR])

* $p<0.05$ vs. premenopausal patients with T2DM

\# $p<0.05$ vs. postmenopausal patients without T2DM

$\& p<0.05$ vs. premenopausal patients without T2DM

$\mathrm{BMI}=$ Body mass index; $\mathrm{SBP}=$ systolic blood pressure; $\mathrm{DBP}=$ Diastolic blood pressure; $\mathrm{WC}=$ waist circumference; T2DM=type 2 diabetes; $T G$ = triglyceride; $L D L=L o w$ dense lipoprotein; $H D L=$ high dense lipoprotein; MDA=Malondialdehyde; FBS=Fasting blood sugar; $\mathrm{HbA1c}=$ hemoglobin A1c; ox-LDL= oxidized Low dense lipoprotein, $n=$ number

Table4. Ten-year ASCVD risk score and metabolic syndrome of Premenopausal and Postmenopausal women with T2DM (268) and without T2DM (107) 


\begin{tabular}{|c|c|c|c|c|c|}
\hline & \multicolumn{2}{|l|}{ T2DM } & \multicolumn{3}{|l|}{ Non-T2DM } \\
\hline & $\begin{array}{l}\text { Premenopausal } \\
\text { women }\end{array}$ & $\begin{array}{l}\text { Postmenopausal } \\
\text { women }\end{array}$ & $\begin{array}{l}\text { Premenopausal } \\
\text { women }\end{array}$ & $\begin{array}{l}\text { Postmenopausal } \\
\text { women }\end{array}$ & $\begin{array}{l}p- \\
\text { value }\end{array}$ \\
\hline & $N=79$ & $N=189$ & $\mathrm{~N}=54$ & $\mathrm{~N}=53$ & \\
\hline $\begin{array}{l}\text { 10-year } \\
\text { ASCVD risk }\end{array}$ & $9.36 \pm 4.51 \& \#$ & $10.61 \pm 4.22 \& \#$ & $3.20 \pm 0.03 \#$ & $4.18 \pm 0.47$ & $<0.001$ \\
\hline \multicolumn{6}{|l|}{ score(\%) } \\
\hline $\begin{array}{l}\text { Risk groups, } \\
n(\%)\end{array}$ & & & & & 0.021 \\
\hline $\begin{array}{l}\text { - Low } \\
\operatorname{risk}(<5 \%)\end{array}$ & 16(21.5)\&\# & 37(19.75)\&\# & 30(55.5)\# & $22(41.5)$ & \\
\hline $\begin{array}{l}\text { - Borderline } \\
\text { risk }(5 \% \leq \text { and } \\
<7 \%)\end{array}$ & $7(8.8)$ & $15(7.9)$ & $5(9.2)$ & $4(7.5)$ & \\
\hline $\begin{array}{l}\text { - Intermediate } \\
\text { risk }(7 \% \leq \\
\text { and }<19.5 \%)\end{array}$ & 22(27.8)\&\# & 66(34.9)\&\# & 6(11.1)\# & 11(20.7) & \\
\hline $\begin{array}{l}\text { - High risk } \\
(\geq 19.5 \%)\end{array}$ & 30(37.9)\&\# & 78(41.2)\&\# & 7(12.9)\# & $13(24.5)$ & \\
\hline $\begin{array}{l}\text { Metabolic } \\
\text { syndrome, } \\
\mathrm{n}(\%)\end{array}$ & 65(82.2)\&\# & 170(89.9)\&\# & 11(20.3)\# & 23(43.3) & 0.001 \\
\hline$A S C V D=$ athero & erosis cardiovas & ar disease; $n=n$ & & & \\
\hline
\end{tabular}

Table 5. correlation coefficients, univariate and multivariate linear regression analyses of the relationships between ox-LDL and biochemical and anthropometric parameters in 594 participants 


\begin{tabular}{|c|c|c|c|c|c|c|}
\hline \multirow[t]{2}{*}{ Variables } & \multicolumn{2}{|c|}{ Correlation } & \multicolumn{2}{|c|}{ Univariate Regression } & \multicolumn{2}{|c|}{ Multivariate Regression } \\
\hline & r & $\rho$ & OR & $\rho$ & OR & $\rho$ \\
\hline age & 0.09 & 0.055 & 1.38 & $<0.001$ & 1.22 & 0.156 \\
\hline BMI & 0.02 & 0.636 & 1.17 & 0.696 & 1.10 & 0.772 \\
\hline WC & 0.04 & 0.341 & 1.09 & 0.404 & 1.01 & 0.541 \\
\hline Duration of diabetes & 0.09 & 0.210 & 1.18 & 0.367 & 1.08 & 0.492 \\
\hline SBP & 0.03 & 0.598 & 1.47 & 0.011 & 1.10 & 0.103 \\
\hline TG & 0.68 & $<0.001$ & 1.54 & $<0.001$ & 1.27 & $<0.001$ \\
\hline HDL-C & -0.08 & 0.131 & 0.40 & $<0.001$ & 0.78 & 0.244 \\
\hline LDL-C & 0.06 & 0.436 & 1.12 & 0.696 & 1.01 & 0.872 \\
\hline FBS & 0.29 & $<0.001$ & 1.33 & 0.018 & 1.10 & 0.162 \\
\hline $\mathrm{HbA} 1 \mathrm{c}$ & 0.23 & $<0.001$ & 1.34 & 0.021 & 1.12 & 0.189 \\
\hline 10-year ASCVD risk score(\%) & 0.82 & $<0.001$ & - & & - & \\
\hline Metabolic syndrome & 0.61 & $<0.001$ & - & & - & \\
\hline \multicolumn{7}{|c|}{$\begin{array}{l}\text { BMI=Body mass index, } \mathrm{WC}=\text { waist circumference, } \mathrm{SBP}=\text { systolic blood pressure; } \mathrm{HbA} 1 \mathrm{C}=\text { hemoglobin } \\
\mathrm{A} 1 \mathrm{C} ; \mathrm{LDL}-\mathrm{C}=\text { low density lipoprotein cholesterol; } \mathrm{HDL}-\mathrm{C}=\text { high density lipoprotein; } \mathrm{FBS}=\text { fasting blood } \\
\text { sugar; } \mathrm{TG}=\text { triglycerides, } \mathrm{ASCVD}=\text { atherosclerosis cardiovascular disease }\end{array}$} \\
\hline
\end{tabular}

\section{Figures}



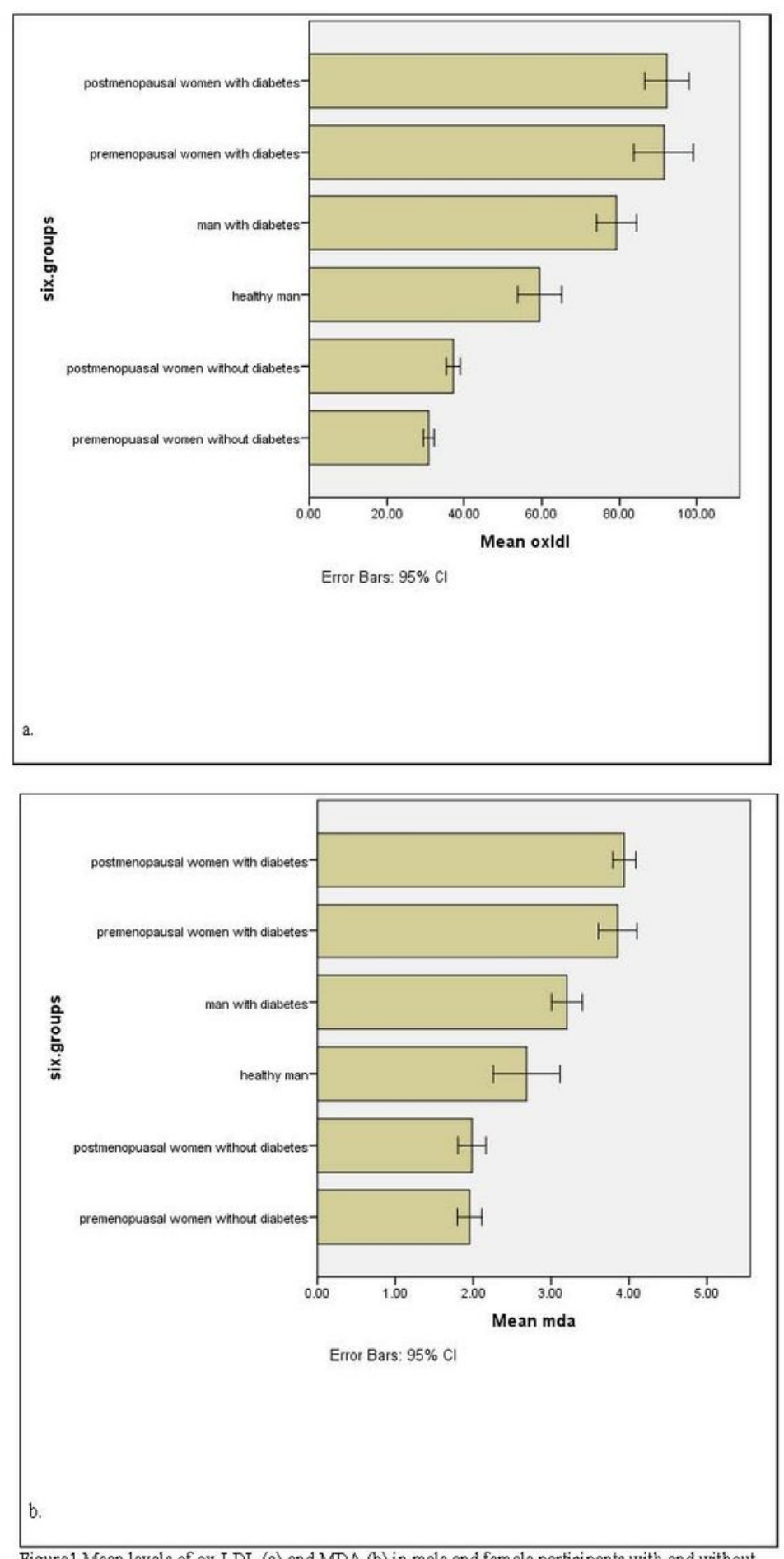

Figure1.Mean levels of ox-LDL (a) and MDA (b) in male and female participants with and without T2DM

Figure 1

Mean levels of ox-LDL (a) and MDA (b) in male and female participants with and without T2DM 


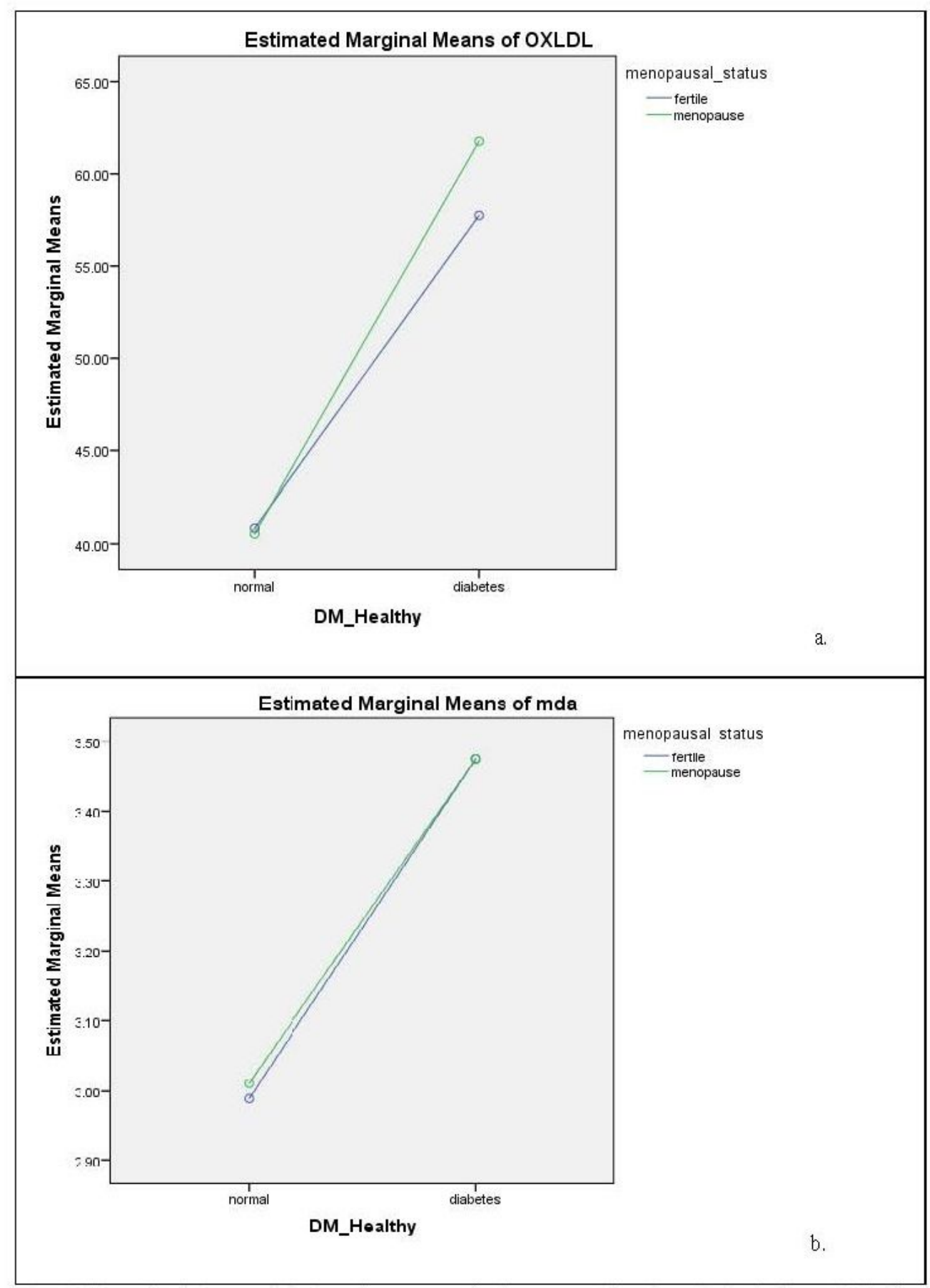

Figure2.Interaction between diabetes and menopausal statues among female participants for ox-LDL (a) and MDA (b) serum levels

\section{Figure 2}

Interaction between diabetes and menopausal statues among female participants for ox-LDL (a) and MDA (b) serum levels 


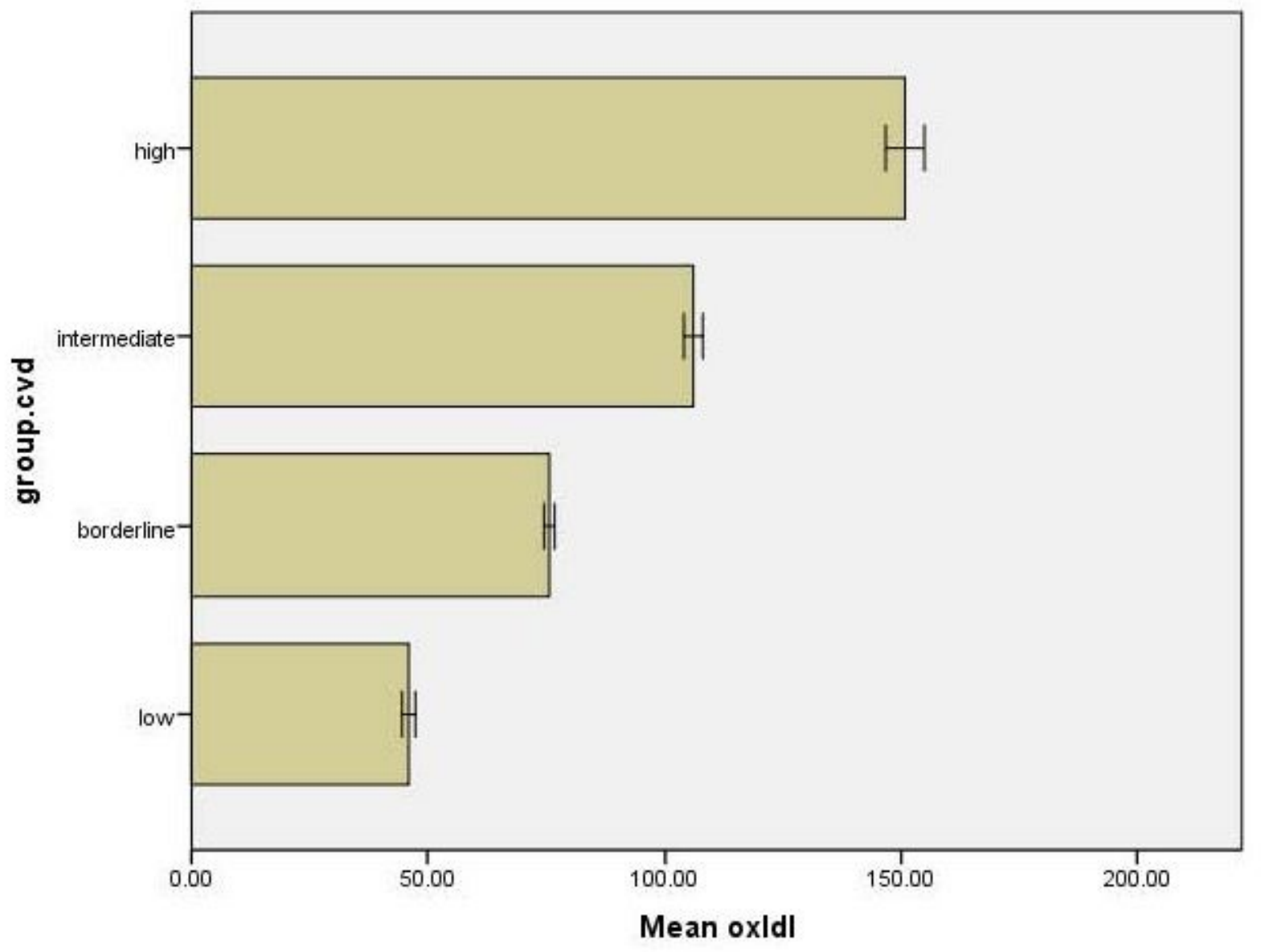

Error Bars: $95 \% \mathrm{Cl}$

Figure 3. Mean levels of ox-LDL in four risk groups of ASCVD

\section{Figure 3}

Mean levels of ox-LDL in four risk groups of ASCVD 